CORRECTION

\title{
Correction: Group prenatal care experiences among pregnant women in a Bangladeshi community
}

\author{
Marufa Sultana, Nausad Ali, Raisul Akram, Tania Jahir, Rashidul Alam Mahumud, Abdur \\ Razzaque Sarker, Ziaul Islam
}

The affiliation for the seventh author is incorrect. Ziaul Islam is not affiliated with \#5 but with \#3: Health System and Population Studies Division, International Centre for Diarrheal Disease Research, Bangladesh (icddr,b), Dhaka, Bangladesh.

\section{Reference}

1. Sultana M, Ali N, Akram R, Jahir T, Mahumud RA, Sarker AR, et al. (2019) Group prenatal care experiences among pregnant women in a Bangladeshi community. PLoS ONE 14(6): e0218169. https://doi. org/10.1371/journal.pone.0218169 PMID: 31188891

\section{Gopenaccess}

Citation: Sultana M, Ali N, Akram R, Jahir T, Mahumud RA, Sarker AR, et al. (2019) Correction: Group prenatal care experiences among pregnant women in a Bangladeshi community. PLOS ONE 14 (7): e0220816. https://doi.org/10.1371/journal. pone. 0220816

Published: July 31, 2019

Copyright: ๑ 2019 Sultana et al. This is an open access article distributed under the terms of the Creative Commons Attribution License, which permits unrestricted use, distribution, and reproduction in any medium, provided the original author and source are credited. 